


\title{
Markering af propriumsfunktion ved omvendt ledstilling
}

\author{
Af Line Sandst
}

In this article, I discuss a type of proper name that is rarely discussed among linguistics and name researchers, however often found among the category of commercial names in the linguistic landscapes in cities. The proper name type differs from other proper name types due to its in Danish unconventional structure of having the part of the compound that describes the locality as the first part of the expression, e.g. Café Sommersko, and not as the last part of the compound, e.g. *Sommerskocaféen that is the common structure in Danish and other Germanic languages.

I argue that the unconventional word formation evokes the instant notion of proper name status, hence has the ability to bypass the time factor that expressions needs in order to obtain proper name status. Therefore, the unconventional expression can be used to exploit the untapped linguistic possibility in Danish language for name givers to form instant proper names.

Kommercielle navne (navne på butikker og erhverv) udgør den måske mest produktive navnetype, når det gælder dannelsen af nye navne. Navne (proprier) kan dannes af forhåndenværende ord eller fraser, hvorved der opstår homonymi imellem to enslydende udtryk, eller de kan dannes som unikke udtryk uden homonymi. Især i førstnævnte tilfælde spiller den tidslige faktor en stor rolle for, om og hvornår udtrykket etableres i navnefunktion for en bred navnebrugerkreds på tværs af generationer og miljøer. ${ }^{1}$ Når det sker, træder den monoreferentielle, og egentlig propriale, funktion i forgrunden, imens forestillingen om en klasse af ting træder i baggrunden (Gernsbacher 1997, Müller 2010, Brédart 2016). Dermed opstår sameksistens af to enslydende udtryk, et fænomen der også kendes som layering (Hopper 1991). Det vil sige, at hvis et udtryk som fx pizzahuset dannes, kan det i en talesprogssituation være vanskeligt at vide, om der menes et hvilket som helst, men specifik refererende og bestemt pizzahus (forestillingen om en klasse af ting er vakt), eller om der menes det kommercielle erhverv Pizzahuset, som ligger på Gothersgade i København (monoreferentiel reference). I sidstnævnte tilfælde er konventionen proprium opstået, der i talesprogssituationen fordrer konsensus om udtrykkets funktion som netop proprium i den pågældende talesprogs-

1 Her ser jeg bort fra lejlighedsdannelser og navnedannelser i mindre sprogsamfund som fx i familier, vennekredse og lignende. 
situation. Dette kan være sket gennem en dåbshandling, men dog oftere i talesprogssituationer ved gentagelse af udtrykket i proprial funktion over tid i forskellige kontekster (Andersson 1994, Ainiala, Saarelma \& Sjöblom, 2016: 23). Proprier i det lingvistiske landskab i byerne kan imidlertid mere entydigt afkodes som proprier i homonyme situationer, da de som skriftfunderede tekster alt overvejende placeres inden for diskursen for propriers placering i byen, hvorigennem den grammatiske kategori kommunikeres visuelt (for mere herom se Sandst \& Syrjälä, Sandst 2016: 93-145).

I det følgende præsenterer jeg et studie af en navnetype, der strukturelt har foranstillet lokalitetsbeskrivende led (Café Sommersko, Salon Zisar, Kontorfallesskabet 5tested m.fl.). Gennem bruddet med den almindelige opbygning i dansk sprog har navnetypen potentialet til at omgå den eventuelle tidslige faktor og altså dannes som øjeblikkeligt proprium i en bred navnebrugerkreds på tværs af tale- og skriftsprog. Trods dette særegne kendetegn er navnetypen sparsomt beskrevet i danske grammatikker og i den øvrige litteratur. Mest indgående er navnetypen behandlet i en kortfattet artikel fra 1988, hvor Bent Jørgensen karakteriserer navnetypen som »fast appositionel markering af ny denotation « (Jørgensen 1988: 115-118). I Hansen og Heltofts grammatik fra 2011 benævnes navnetypen som »proprium som efterstillet adled« (2011: 515), imens Paul Diderichsen fokuserer på trykfordelingen i stednavne af denne konstruktion i Elementcer Dansk Grammatik første gang udkommet i 1946.

Med udgangspunkt i disse lakoniske beskrivelser, der oftere nævner end egentlig karakteriserer, præsenterer jeg i nærværende artikel mine observationer af navnetypen samt indledende analytiske spadestik med udgangspunkt $i$ empiriske forekomster indsamlet i bydelen Indre by i København i perioden 2014-15.

\section{Baggrund}

Jørgensens artikel udsprang af et mindre studie af navnetypen, som er det eneste af sin art, der beskriver den unge navnetype. I artiklen anfører Jørgensen bl.a. eksemplerne Fiskehuset Damsø og Sygekassen Vanløse. Strukturelt strider dannelsen imod reglerne i dansk sprog, hvor der normalt er efterstillet artsled. Et artsled er det led i et sammensat stednavn, som betegner lokalitetens art, fx -by, -skov eller -rup (et oprindeligt torp, der betyder udflytterbebyggelse og dateres til vikingetid og middelalder). 
Dertil indtager det foranstillede beskrivende artsled »et meget fast forhold til det egentlige navn« (Jørgensen 1988: 115), og spørgsmålet er derfor, hvordan navnetypen skal opfattes.

Jørgensen mener, at opkomsten af navnetypen skyldes markering af andetleddet som genbrug af et allerede etableret stednavn anvendt $i$ en ny funktion om et nyt slags denotatum, altså en ny slags lokalitet, der ønskes benævnt. Af nævnte eksempler ovenfor anvendes Vanløse således allerede som bebyggelsesnavn, men genanvendes i det kommercielle navn (Sygekassen Vanløse) med foranstillet beskrivende led Sygekassen for at markere, at det er en anden lokalitet end byen, der menes. I et undersøgelsesområde på 250.000 kvadratmeter i Indre By i København, ses følgende forekomster af navnetypen:

\begin{tabular}{l}
\hline Kommercielle navne med foranstillet lokalitetsbeskriver \\
ADVOKATFIRMAET SVANHOLM \\
Boutique soavita Kunsthåndværk fra Madagaskar \\
BOUTIQE TAEKO \\
CAFÉ DAN TURELL 1977 \\
Café Nick \\
Café Norden \\
Café Rex \\
CAFÉ SOMMERSKO $\underline{1976}$ \\
CAFÉ VICTOR $\underline{1981}$ \\
DEN SELVEJEDE INSTITUTION MUSIK \& TEATER \\
Diskotek Be Proud \\
DOMSTOLSSTYRELSEN DANMARKS DOMSTOLE \\
EJENDOMSSELSKABET J. HALDS GAARD \\
$\underline{\text { FISKERIAKTIESELSKABET ICEFISH }}$ \\
FORLAGET PRESSTO \\
FORLAGET SCALA. \\
FRISØR CESARE \\
Frisør Stender \\
GALERIE BECHMAN \\
GALERIE EDELING \\
GALLERI K \\
galleri NB \\
Galleri Sct Gertrud \\
GO-GO BAR Beverly Hills NIGHTCLUB gentlemen's club \\
Hælebaren City \\
intercoiffure MONDIAL \\
Konditori Antoinette café \& conditori \\
Kontorfællesskabet 5tested \\
\end{tabular}




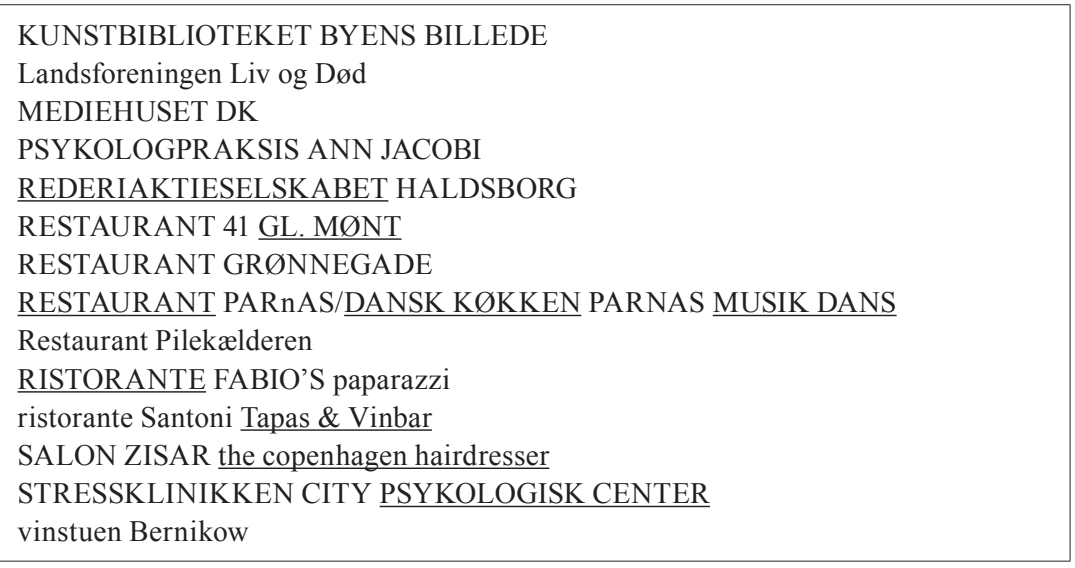

Tabel 1: 42 kommercielle navne med foranstillet beskrivende element/artsled indsamlet i perioden 2014-2015 i bydelen Indre By i København (se Sandst 2016: 38-53 om metode og analyse). Flere af de foranstillede artsled skrives med en anden eller mindre skrifttype, der visuelt markerer forskel imellem de to led og kan sigte til det foranstillede leds faste, men ikke obligatoriske brug. Dette er gengivet ved understregning, der endvidere dckker over tillagsinformationer, der specificerer varesortiment, årstal for hvornår det navnbcerende erhverv grundlagdes m.m. Navnene er her gengivet med store og små bogstaver, som de fremstod på skiltene $i$ byen, men normaliseres $i$ brødteksten $i$ det følgende. Andre modaliteter som farve, forskellige skrifttyper og komposition er ikke gengivet, men kan studeres normere i Sandst 2016.

Undersøgelsesområdet indeholdt i alt 948 individuelle lokalitetsforankrede løbenavne, hvoraf 42 proprier har foranstillet lokalitetsbeskrivende element. De 948 navne dækker over en række forskellige navnetyper, der ud over kommercielle navne indbefatter gadenavne, navne på pladser, huse, en kirke, en kanal (Slotskanalen) m.fl. Gruppen af ikke-kommercielle navne udgør i alt 71 proprier, og der er ingen proprier i den bredtfavnende kategori, der er dannet med foranstillet lokalitetsbeskrivende element. I dette datamateriale knytter navnedannelsen sig altså specifikt til kategorien kommercielle navne, som i undersøgelsesområdet udgør den mest prominente andel af data på i alt 877 proprier. Procentvis er ca. $4,8 \%$ af de kommercielle navne i materialet således dannet med foranstillet lokalitetsbeskrivende element. Det er altså en lille navnegruppe, som dog samtidig er vanskelig at overse.

Appositionsforholdet er fast, men ikke obligatorisk, mener Jørgensen. Han afviser endvidere konstruktionen som et fuldt navn, da det medfører, at der enten findes navne med foranstillet artsled »noget hidtil uset og for 
de germanske sprog aldeles fremmed« (ibid.: 116), eller at navnetypen må opfattes som reciprokeringer. Reciprokeringer er de propriale forekomster af stednavne, som står $\mathrm{i}$ et indbyrdes afhængighedsforhold til hinanden, som fx Store Brodersby og Lille Brodersby, Sønder Brarup og Nørre Brarup osv. Navneparrene både forudsætter hinanden, da der ikke ville være en store-forekomst uden en lille-forekomst, og indgår i et kronologisk forhold til hinanden, da de reciprokerende tilføjelser først opstår ved fremkomsten af den yngre bebyggelse og den heraf afledte sproglige nødvendighed af at kunne adskille de to bebyggelser fra hinanden. ${ }^{2}$

Jørgensen afviser imidlertid muligheden, at navnetypen skulle være en reciprokering »da leddene $\mathrm{i}$ en reciprokering indgår $\mathrm{i}$ et underordningsforhold [hvor man får] relationen Borød Flinterup = Flinterup forskellig fra Borød, mens man i fx Sygekassen Vanløse har relationen Sygekassen Vanløse $=$ sygekassen $=$ Vanløse $«$ (ibid.). Relationen mellem leddene er med andre ord ligeværdige.

\section{Proprialiseringsstrategi og utilpassede lån}

I navnetypen med foranstillet lokalitetsbeskrivende artsled har begge led i dannelsen altså en ligeværdig relation. Det kunne udtrykkes som, at de to navneelementer i Sygekassen Vanløse hører sammen, som om der var et usynligt kolon imellem den foranstillede lokalitetsbeskriver og andetleddet.

Jørgensen opregner to muligheder for, hvordan navnetypen er opstået. Dels kan navnetypen være inspireret af navnedannelser fra andre sprog, dels er:

Tilkomsten af ny denotation [...] forbundet med tilkomsten af en ny denotatumskategori, men samtidig vil den normale situation være den, at den primære navnebærer bevarer sit navn. Den faste apposition bliver derfor en nødvendighed til sproglig markering af, at der nu er tale om den betydningssekundære navnebrug, og typen er dermed en god indikator for tilkomst af ny denotation. (ibid.)

2 Se Bent Jørgensens Reciprokering (1977) for en udførlig indføring i fænomenet, som også indeholder navnepar med mere underfundige reciprokerende led, der knytter navneparrene sammen. 
Forklaringsmodellen passer til navnedannelserne Fiskehuset Damsø og Sygekassen Vanløse, som danner udgangspunktet for Jørgensens undersøgelse, og begge har et etableret stednavn som andetled. I mit materiale er der imidlertid ikke tale om genbrug af etablerede stednavne som andetled. Derimod kan der observeres et miks af proprier, appellativer og quasiord som sidste led i navnet, ligesom navnetypen anvendes inden for mange forskellige denotatumskategorier både caféer, forlag og et diskotek (Café Sommersko, Forlaget Pressto, Diskotek Be Proud). Dette kunne pege i retning af, at navnetypen kunne have en oprindelig indlånt struktur som ophav.

Navne med foranstillet artsled kendes fra romanske sprog. Som det fremgår af tabellen ovenfor, udgøres en stor del af de foranstillede lokalitetsbeskrivende led af indlånte ord fra eller via romanske sprog, således café, galleri, salon, butik (boutique), diskotek og restaurant. En nærliggende slutning kunne drages ved den antagelse, at fx flere cafénavne med foranstillet lokalitetsbeskriver, kunne være dannet efter fransk forbillede: Café Dan Turèll 1977, Café Nick, Café Norden, Café Rex, Café Sommersko 1976 og Café Victor 1981. Når Jørgensen peger på, at navnedannelsen kan have udenlandsk forbillede (ibid.: 118), viser mit materiale altså det samme.

Jørgensen antyder, men skriver aldrig direkte, at navnetypen fungerer, som det jeg ved tidligere lejlighed har betegnet som en proprialiseringsstrategi (Sandst 2016), da der dannes et instant name (Nicolaisen 1997, Andersson 1996: 23). Det betyder, at den morfologiske struktur kan benyttes af navngivere, der ønsker at undgå homonymisk tvetydighed og danne et entydigt proprium her-og-nu for en bred navnebrugerkreds. Fra et sprogbrugsperspektiv kan det strukturelle lån beskrives som et funktionsdrevet valg af navnetype hos navngiverne, der kan ses i et kontinuum fra bevidst til ubevidst motivation

from those that are not at all voluntary (e.g. phenomena known as 'interference' or 'transfer,' or errors in the selection of the appropriate language form), [...] to those that are conscious and deliberate (such as language mixing for stylistic purposes) (Matras 2010: 83).

Netop ved sprogstørrelsens særpræg som en ikke-germansk orddannelsestype kan propriumsfunktion markeres øjeblikkeligt, da orddannelsesmåden mig bekendt kun kendes ved proprier. På denne måde kan sprogstør- 
relsen dannes af forhåndenværende ordstof på en »proprial facon«, hvor homonymi undgås, og der markeres propriumsfunktion fra start.

Men navnetypen kan også have haft særlige produktive perioder i moderne tid forankret til moder og tendenser i opkomsten af lokalitetstyper i det urbane miljø. Fx kendes lokalitetstypen café i Europa fra 1600-tallet. Dog fik cafékulturen først for alvor sit indtog i Danmark i løbet af 1970'erne efter fransk og italiensk forbillede »^ørst med etableringen af Café Sommersko i København i 1976, snart efter med caféer over hele landet« (DSD). Med (gen)etableringen af den 'indlånte' lokalitetstype, kunne det tænkes, at navnedannelsesmåden også blev (gen)indlånt, da navngiverne dermed ville kunne signalere noget særlig fransk (og italiensk) via strukturen i navnedannelsen. Der ville dermed være tale om et sociolingvistisk motiveret lån som indgang til grammatikaliseringen (jf. Heine \& Kuteva, 2010: 88), hvor

speakers feel pressure to demonstrate competence in a prestige language, or else that it is internal to language, in the sense that speakers generalize certain vocabulary items across their repertoire for the sake of convenience, irrespective of the function of these vocabulary items, as long as there are no structural obstacles that stand in the way of their integration into the recipient language (Matras, 2010: 78).

Orddannelsen kendes imidlertid også i andre germanske sprog, fx fra de engelske proprier River Thames og Mount Everest. Floden Thames nævnes første gang i kilderne i 51 f.Kr. i formen Tamesis (Ekwall, 1928/1968, s. 402), men et senere belæg fra ca. 730 e.Kr. benævnes floden i en latinsk kilde som fluuium Tamensem, altså med et latinsk foranstillet flod (ibid.). Ekwall angiver ingen kilder med River Thames, imens der på John Ogilbys kort over vejruter i England fra 1675 snart skrives Thames flu., fluvius eller River Thames (Ogilby 1971).

Konstruktioner med foranstillet River før proprium angiver Oxford English Dictionary (OED) som et nyere fænomen med første belæg fra ca. 1398 (OED, river) »now chiefly in British English referring to British rivers and certain other major, historically important rivers, as the Nile, Rhine, Ganges etc.« (ibid.). Imidlertid indeholder samtlige belæg på konstruktionen river + proprium også et the (Pe ryuer Gyon, The ryver Ban, the riuer Styx m.m.), og det er derfor ikke entydigt, om river skal opfattes som en fast del af navnet, eller som et forklarende element i den syntaktiske enhed. 
Mount Everest er en ung navnedannelse fra 1857. Bjerget er navngivet efter Sir George Everest (1790-1866), der ledte kortlægningen af Indien og Himalaya (OED, Everest), men konstruktionen med et foranstillet Mount(ain) er ældre og kan dateres til samme periode, som hvor det foranstillede river + proprium begynder at optræde i kilderne (jf. »To mount synai forð he nam « i et belæg af 1325 af en afskrevet kilde fra 1250 (OED, Mount)). Der tegner sig dermed et billede af, at foranstillet artsled i proprierne indledningsvist fandtes i de romansksproglige overleveringer, og først senere fandt vej ind i det engelske sprog, hvorved konstruktionen altså må opfattes som en nyere (indlånt) orddannelse, som tilsyneladende er specifik for proprier. Når Jørgensen anfører, at navne med foranstillet artsled er fremmed for germanske sprog (Jørgensen 1988: 116), understøtter overleveringerne altså udsagnet.

Materialet er for lille til at sige noget entydigt om fordelingen af, hvornår der bruges bestemt eller ubestemt form ved den foranstillede lokalitetsbeskriver i danske forekomster. Jørgensen mener, at navnetypen i konstruktionen ubestemt form + proprium er tilknyttet de to denotationskategorier villaer og hotel- og restaurationsbranchen. Som det fremgår af tabellen ovenfor, findes denne konstruktion også ved andre denotationskategorier som fx frisører.

Der tegner sig nogle spæde konturer blandt eksemplerne fra data, der kunne antyde, at ubestemt form særligt bruges ved indlånte ord fra romanske sprog, hvorfra navnedannelsen kendes i den nøgne form (jf. café, salon, frisør og restaurant/ristorante), mens de substantiver, der er og muligvis opfattes mere hjemlige, antager bestemt form, således fx Vinstuen Bernikow, Haelebaren City og Advokatfirmaet Svanholm. I det første tilfælde kunne der være tale om mønsterpåvirkning fra de(t) sprog, hvor strukturen indlånes fra, hvorfor bestemthedsmarkeringen udebliver, imens der i det andet tilfælde kunne være tale om hjemlige dannelser med udgangspunkt i den indlånte struktur, hvor bestemthed markeres. Men det kræver en større og systematisk undersøgelse at af- eller bekræfte tesen.

\section{Konklusion}

Navnetypen er veletableret og har været kendt i Danmark i mindst 200 år (Jørgensen 1988: 115). Endvidere har den bredt sig til forskellige denotationskategorier, og den er særligt frekvent i de navnetyper, der hører til den kommercielle verden. Grundet dansk sprogs ordstilling er den velegnet til 
at danne utvetydige og øjeblikkelige proprier, da der ikke opstår homonymi med andre udtryk. Det tyder samtidigt på, at konstruktionen med foranstillet lokalitetsbeskriver er af nyere, indlånt oprindelse.

Navnet Café Sommersko vidner om, at navnetypen anvendes som andet end markering af ny denotation ved genbrug af et allerede etableret proprium som navneelement. Dertil havde det været tilstrækkeligt at kalde caféen for *Sommerskocafé(en), hvis den blotte association havde været målet. Gennem den omvendte ordstilling skabes et navn, der øjeblikkeligt markerer proprium, associerer til romanske sprog og kultur, og samtidigt indeholder potentialet for de associationer, der fremkommer ved *Sommerskocafé(en). Orddannelsesmåden kan altså anvendes som markering af propriumsfunktion.

Om den ubestemte form breder sig til navnedannelser med foranstillede oprindelige fællesnordiske ord (eller ved afklimatiserede låneord, der opfattes som danske) er uvist. Jeg har excerperet grænsetilfældet Guldsmed Bjerg Van Mackelenbergh fra et butiksskilt. Da guldsmed både kan betyde »kunsthåndværker der fremstiller smykker« og »forretning hvor

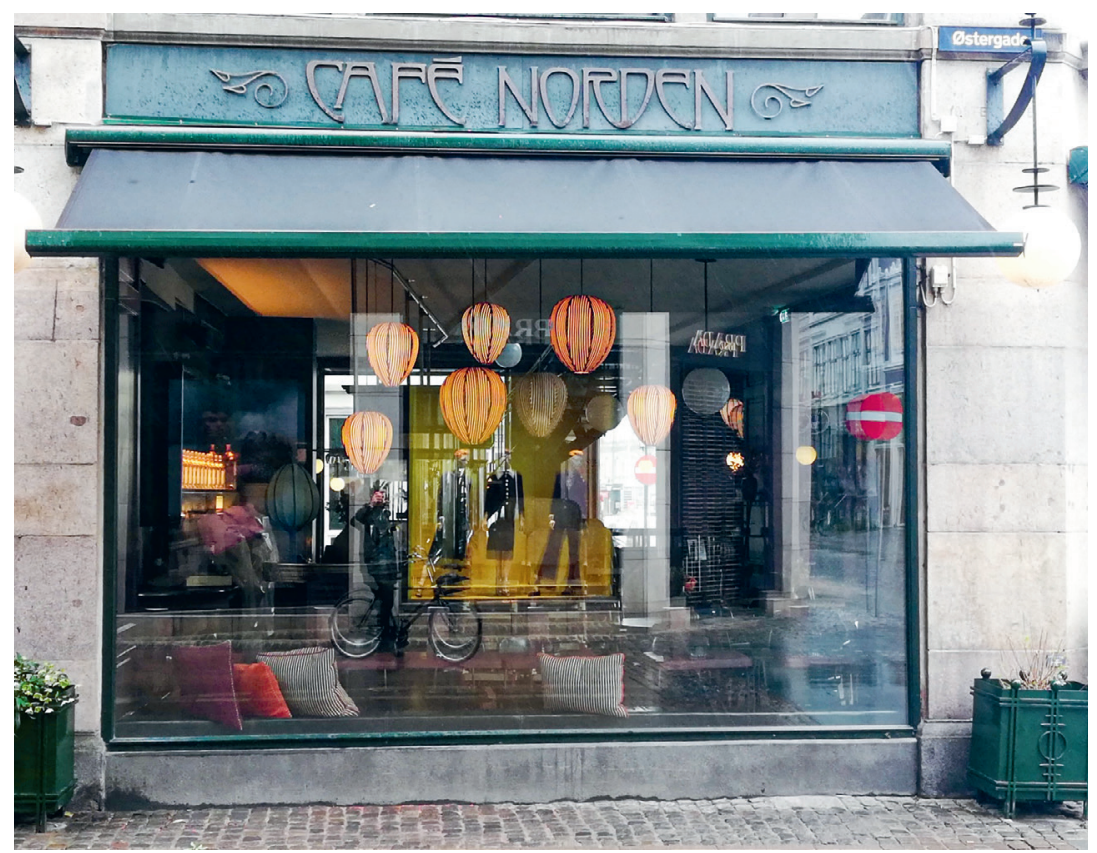

Café Norden. Foto: Carl-Emil Prehn Andersen 
man køber smykker« (DDO) kan det ret beset ikke afgøres, om der menes det ene eller det andet. Det samme gælder i øvrigt for substantivet frisør.

Appositionsforholdets faste, men ikke obligatoriske forbindelse illustreres visuelt i flere navne, hvilket fremgår af tabellen ovenfor markeret ved understregninger. Flere foranstillede lokalitetsbeskrivende led skrives nemlig med en anden eller mindre skrifttype i forhold til navnets andetled. Forskel i skrifttyper og -størrelse ses ofte i teksterne på butiksskilte med proprier i de lingvistiske landskaber, og kan have flere forskellige betydninger (se fx Sandst 2016: 113-128). I proprierne med foranstillet lokalitetsbeskrivende led kunne forskellene også sigte til (eller afstedkomme) opfattelsen af en fast, men ikke obligatorisk forbindelse mellem leddene.

Der er to måder at danne proprier på. Enten som unikke udtryk eller med udgangspunkt i eksisterende ord eller fraser. Men proprier er også konventioner, der skal tillæres, hvilket kræver tid og konsensus i en navnebrugerkreds. De unikke navnedannelser har deres styrke ved fraværet af homonymi, hvorved forvekslingsmulighederne med andre ord og grammatiske klasser minimeres. Til gengæld er det vanskeligere at forbinde propriet med det, det betegner, da det ofte ikke beskrives, hvad det skulle betegne grundet manglede homonymi.

Dog virker orddannelsesmåden med foranstillet lokalitetsbeskriver i fast appositionelt forhold til andetleddet som en navnedannelsesmåde, der kan skabe øjeblikkeligt proprium på tværs af tale- og skriftsproget. Fordi orddannelsen er fremmed for germanske sprog, har den været stort set uudnyttet, og derfor kan strukturen bruges ved navnedannelse til at markere øjeblikkeligt proprium med.

\section{Litteratur}

Ainiala, Terhi, Saarelma, Minna \& Sjöblom, Paula. 2016. Names in Focus - An Introduction to Finnish Onomastics. Helsinki: Finnish Literature Society.

Andersson, Thorsten. 1994. Onomastiska grundfrågor. i: Kristoffer Kruken (red). Den ellevte nordiske navneforskerkongressen. NORNA-rapporter 60, Uppsala: NORNA-Förlaget, s. 15-43.

Brédart, Serge. 2016. Names and Cognitive Psychology. In: Carole Hough (red.), The Oxford Handbook of Names and Naming. Oxford: Oxford University Press, 476-487.

DDO $=$ Den Danske Ordbog. Det Danske Sprog- og Litteraturselskab. Online: www.ordnet.dk

Diderichsen, Paul. 1957. Elementcer dansk grammatik. 2. udgave. København. 
DSD = Bjarne Kildegaard: café i Den Store Danske, Gyldendal. Hentet 10. juli 2019 fra: http://denstoredanske.dk/index.php?sideId=53439

Ekwall, Eilert. 1928/1968. English River-names. Oxford: Oxford University Press.

Gernsbacher, Morton Ann. 1997. Attenuating Interference during Comprehension: The Role of Suppression. The Psychology of Learning and Motivation, Scopus (37), s. 85-104.

Hansen, Erik \& Heltoft, Lars. 2011. Grammatik over det Danske Sprog. bd. 1-3. Aarhus.

Heine, Bernd \& Tania Kuteva. 2010. Contact and Grammaticalization. I: Raymond Hickey (red). The Oxford Handbook of Language Contact. Oxford, UK: Wiley $\square$ Blackwell, s. 86-105.

Heine, Bernd (eds.). 1991. Approaches to Grammaticalization, vol 1, s. 17-36. Amsterdam.

Hopper, Paul J. 1991. On some principles of grammaticazation, i: Elizabeth Closs Traugott \& Bernd

Jørgensen, Bent. 1977. Reciprokering. København.

Jørgensen, Bent. 1988. Fast appositionel markering af ny denotation, i: NORNArapporter 37, s. 115-118. Uppsala.

Matras, Yaron. 2010. Contact, Convergence, and Typology, i: Raymond Hickey (red). The Handbook of Language Contact. Oxford, UK: Wiley $\square$ Blackwell, s. 86-105.

Müller, Horst M. 2010. Neurolinguistics: The Special Role of Proper Names. Chinese Journal of Physiology 53:6, 351-358.

Nicolaisen, W. F. H. 1997. One name but many systems, i: You name it, s. 57-62. Helsinki.

OED=Oxford English Dictionary: "Everest": https://www-oed-com.zorac.aub. aau.dk/view/Entry/65312?redirectedFrom=everest\# eid. "Mount": https:// www-oed-com.zorac.aub.aau.dk/view/Entry/122888?rskey=uuZpib\&resu lt=1\&isAdvanced=false\#eid. "Thames": https://www-oed com.zorac.aub. aau.dk/view/Entry/200113?redirected From=thames\#eid. "River": https:// www-oed-com.zorac.aub.aau.dk/view/Entry/166422?rskey=Rt9MYC\&result $=1 \&$ is Advanced $=$ false\#eid

Ogilby, John. 1971. Road Maps of England and Wales, fra John Ogilby Britannia 1675, Osprey, Reading.

Sandst, Line. 2016: Urbane Stednavne - storbyens sproglige dimension. Ph.d.afhandling, København: Københavns Universitet.

Sandst, Line \& Väinö Syrjälä (under udgivelse) "Proper names in the Linguistic Landscape: Theoretical challenges in a Multimodal Discourse." i Löfdahl, Maria, Michelle Waldispühl, Lena Wenner (eds.). Names in Writing. Namn $i$ skrift. Göteborg: Meijerbergs institut. 